possible that even a vaccine that is highly effective today would need to be updated and readministered periodically. Ralph Baric, a microbiologist at the University of North Carolina School of Medicine in Chapel Hill, has found a potential work-around that might extend a vaccine's lifespan. Baric's group created chimeric VLPs or cocktails of VLPs containing proteins from several different norovirus strains isolated over two decades. As he reported at the American Society for Virology meeting in July in State College,
Pennsylvania, the more diverse vaccine constructs induced a more broadly blocking immune response in mice than standard VLP vaccine designs.

Arntzen firmly believes that any obstacles can be overcome. His mussel eating depends on it. "It's time and money," he says. "I honestly don't see any scientific barriers at this point."

\section{Cassandra Willyard}

1. Chen, Z. et al. J. Virol. 87, 9547-9557 (2013).
2. Hall, A.J. et al. Emerg. Infect. Dis. 19, 1198-1205 (2013).

3. Payne, D.C. et al. N. Engl. J. Med. 368, 1121-1130 (2013).

4. Hall, A.J., Curns, A.T., McDonald, L.C., Parashar, U.D. \& Lopman, B.A. Clin. Infect. Dis. 55, 216-223 (2012).

5. Bartsch, S.M., Lopman, B.A., Hall, A.J., Parashar, U.D. \& Lee, B.Y. Vaccine 30, 7097-7104 (2012).

6. Simmons, K., Gambhir, M., Leon, J. \& Lopman, B. Emerg. Infect. Dis. 19, 1260-1267 (2013).

7. Atmar, R.L. et al. N. Engl. J. Med. 365, 2178-2187 (2011).

8. Tamminen, K., Lappalainen, S., Huhti, L., Vesikari, T. \& Blazevic, V. PLoS One 8, e70409 (2013).

9. Fang, H., Tan, M., Xia, M., Wang, L. \& Jiang, X. PLoS ONE 8, e63269 (2013).

\title{
'Molecular biocontainment' proposed to ease flu research worry
}

In recent years, influenza viruses with pandemic potential have dominated the headlines: H5N1 bird flu, H1N1 swine flu and, most recently, H7N9, which came onto the radar in March and has since claimed the lives of 44 people as Nature Medicine went to press. Flu agents made news again last month, when scientists proposed experiments to better understand H7N9, including one that would mix this newly identified form of bird flu with various types of human flu to assess the effect of that blending on the pathogen's possible transmissibility to people (Nature 500, 150151, 2013; Science 341, 612-613, 2013).

But at the same time that researchers ponder these 'gain-offunction' experiments, another group has offered a new method of modifying flu viruses to limit the types of species these pathogens can infect. As they report in the September issue of Nature Biotechnology (go.nature.com/XIEC1K), their goal is to make it safer to work with these high-risk infectious agents. "This is a clever technique that eases my mind a great deal," says Ian Lipkin, a virologist at Columbia University's Mailman School of Public Health in New York who was not involved in the new research.

The 'molecular biocontainment' method, honed by Benjamin tenOever and his colleagues at the Icahn School of Medicine at Mount Sinai in New York, involves engineering flu viruses to contain short sequences encoding target sites that cause specific microRNAs in host cells to bind the influenza RNA transcripts, priming them for destruction. TenOever's team engineered two subtypes of the influenza A virus, similar to H5N1, to carry a 21-base-pair-long sequence that complements miR-192, a microRNA found in human and mouse lung cells but not in the respiratory tract of ferrets, which serve as the primary animal model for flu. They then exposed ferrets and mice to these modified viruses and saw that the incorporation of miR-192 target sites had no effect on flu replication and transmissibility in the ferrets, but it did attenuate the pathogenicity of the virus in the mice. In this way, the scientists showed that animals infected with viruses containing species-specific microRNA sequences are protected from illness - suggesting that adding human-specific microRNA sequences to pathogens under study in the lab might protect people.

\section{Disarming enthusiasm}

Shibo Jiang, head of the Laboratory of Viral Immunology at the New York Blood Center, notes that the ability to create viruses that get disarmed when they enter certain species might lessen worries about pandemic viruses getting into the hands of terrorists because the modified strains containing complementary microRNA sequences, such as the miR-192 target, would be unable to replicate in humans. "This strategy could be very helpful in animal models and efficacy studies with highly pathogenic viruses," says Jiang, whose research includes studies with H5N1 and H7N9 viruses.

Meanwhile, the method might have commercial applications. According to tenOever, the molecular biocontainment strategy has appealed to at least one vaccine manufacturer, which contacted him to see if putting a species-specific leash on H7N9 could bring down the biosecurity requirements for producing potential vaccines against bird flu. If lowering the risk of human infection also dropped manufacturing requirements from level 3 biosecurity to level 2 , then vaccine production would be much less expensive.

TenOever says that the technique of engineering viruses to contain microRNA sequences to limit the range of species they can infect could also be used with other highly contagious viruses, such as Ebola or the SARS coronavirus. He worries, however, that some funding agencies might make the addition of microRNA sequences to viruses under study a prerequisite. "I wouldn't want it [the technique] to be imposed on anyone, but it can be a safety precaution," tenOever says. "For the time being, there is no requirement to utilize this technique as a biocontainment method," says Amy Patterson, director of the Office of Science Policy at the US National Institutes of Health.

Some scientists also worry about the unintended consequences of adding microRNA target sites. For example, Richard Webby, an influenza researcher at St. Jude Children's Hospital in Memphis, Tennessee, suggests that more work is needed to ensure that the modification doesn't weaken the strength of infectious agents in species that lack the complementary sequence. "This has to be checked in a number of different viruses and different species, because we've got to be confident there's no impact on the biology of a virus before we spend years doing studies with it," Webby says.

Adding microRNA targets to viruses is attractive because this biosecurity measure doesn't depend on people or equipment to be effective, says Colin Parrish, a virologist at the Baker Institute for Animal Health at Cornell University, in Ithaca, New York. But the specter of a viral escape isn't far from anyone's mind. "Hindsight doesn't really help if a virus jumps," Parrish says. "We still have to keep our guard up."

Elizabeth Devitt 